Avrupa Bilim ve Teknoloji Dergisi

Özel Sayı, S. 416-425, A ğustos 2020

(C) Telif hakkı EJOSAT'a aittir

Arastırma Makalesi
European Journal of Science and Technology

Special Issue, pp. 416-425, August 2020

Copyright (C) 2020 EJOSAT

Research Article

\title{
Dört Mekanum Tekerli Mobil Robot Platformunun Geliştirimesi ve Güvenlik Amacıyla Kullanımı
}

\author{
Musa Matl1 ${ }^{1}$, Raif Bayır ${ }^{2 *}$ \\ ${ }^{1}$ Karabük Üniversitesi, Lisansüstü Eğitim Enstitüsü, Mekatronik Mühendisliği Anabilim Dalı, İstanbul, Türkiye (ORCID: 0000-0002-8440-6950) \\ ${ }^{2}$ Karabük Üniversitesi, Teknoloji Fakültesi, Mekatronik Mühendisliği Bölümü, İstanbul, Türkiye (ORCID: 0000-0003-3155-8771)
}

(Bu yayın 26-27 Haziran 2020 tarihinde HORA-2020 kongresinde sözlü olarak sunulmuştur.)

(DOI: $10.31590 /$ ejosat.780670)

ATIF/REFERENCE: Matlı, M. \& Bayır, R. (2020). Dört Mekanum Tekerli Mobil Robot Platformunun Geliştirimesi ve Güvenlik Amaciyla Kullanımı. Avrupa Bilim ve Teknoloji Dergisi, (Special Issue), 416-425.

$\ddot{\mathbf{O} z}$

Günümüzde yüksek işlem gücüne sahip işlemcilerin artması ile robot çalışmaları hız kazanmıştır. Araştırma konuları arasına robotların gündelik işlerde kulanılması girmiştir. Askeri, sağlık, hizmet, eğlence sektörleri gibi birçok alandaki insan iş gücünün yerini robotların aldığı görülmektedir. Güvenlik görevlilerinin güvenliklerini sağladıkları ortamlarda suç işlenmesini önlemek, can mal emniyetini sağlamak, suç işlemeye karşı caydırıcı tedbirlerin alınması ve olaylara müdahale edilmesi için belirli periyotlarla devriye görevi yapılmaktadır. Bu durum olası bir durumda güvenlik görevlisinin zarar görmesine neden olmaktadır. Ayrıca insan gözü dar bir açıda görmektedir. İnsanın görüsü, algılaması pisikolojik ve fizyolojik etkenlere bağlıdır. Bu çalışmada güvenlik görevlilerinin sorumluluk alanı içerisinde tur atma görevini Mekanum tekerli mobil robot platformu ile yapılabileceği gösterilmektedir. Mekanum tekerlerin çok yönlü hareket kabiliyeti sayesinde robot, ortam içerisinde ve dar alanlarda rahatça hareket etmektedir. Çevrenin algılanmasında ve robotun engellere çarpmaması için LIDAR sensör kullanılmıştır. Deneysel çalışmalarda robot E şekline sahip deney ortamında 5 defa tur atmıştır. Her turu aynı noktadan başlatıp aynı noktada bitirmiştir. Kullanılan donanım ve kinematik yapının bu problem için kullanılabilir olduğu gözlemlenmiştir.

Anahtar Kelimeler: Mekanum teker, Mobil robot, Lazer mesafe sensörü, Bekçi robot.

\section{Four Mecanum Wheeled Mobile Robot Platform Development and Use For Security Purposes}

\begin{abstract}
Robot studies are rising with the increase of processors with high processing power. The use of robots in daily work is among today's topics. For this reason, it is seen that robots replace human labor in many fields such as military, health, service and entertainment sectors. Security guards are patrolled in their provide security zone for crime prevention, deterrence, safety of life and property and hard stop. In a possible situation, the security guard could be damaged. In addition, the human eye sees at a narrow angle. Human's sensation and perception depends on psychological and physiological factors. In this study, it is shown that the mobile robot platform with Mecanum wheels can perform the task of patrol in the area like security guards. Thanks to the omni directional movement capabilities of the wheels, the robot moves comfortably in confined spaces. Robot sense the environment and obstacle with LIDAR sensor. In experimental studies, the robot patrolled 5 rounds in the experimental environment like E shape. He started each round from the same point and finished at the same point. Observed that the hardware and kinematic structure used can be used for this problem.
\end{abstract}

Keywords: Mecanum wheel, Mobile robot, Laser range sensor, Guardbot.

\footnotetext{
* Sorumlu Yazar: Raif Bayır Karabük Üniversitesi, Teknoloji Fakültesi, Mekatronik Mühendisliği Bölümü, İstanbul, Türkiye, ORCID: 0000-00033155-8771, rbayir@karabuk.edu.tr
} 
European Journal of Science and Technology

\section{Giriş}

Gelişen teknoloji klasik robot anlayışından ziyade mobilite kavramını ortaya kaymaktadır. Mobil robotlar insan operatörü olmadan bir yerden bir başkasına otonom olarak hareket edebilen cihazlardır. Robota özel tasarlanmış alanların içerisinde çalışan genel endüstriyel robotların aksine mobil robotlar hedeflerine ulaşabilmek için önceden tanımlanmış çalışma alanlarında serbestçe hareket edebilme özelliklerine sahiptirler. Mobilite kabiliyeti mobil robotlara çok geniş bir uygulama alanı kazandırmaktadır. Mobil kara robotları tekerli mobil robotlar, bacaklı mobil robotlar olarak tanınmaktadırlar. Otonom hava araçları ve otonom sualtı araçları da mobil robot olarak tanınmaktadır. Mobil robot platformları arasında en popüler olanı tekerlekli mobil robotlardır. Çünkü düşük mekaniksel komplekslik ve enerji tüketimi ile özgün uygulamalar için uygundurlar. Bacaklı mobil robotlar standart olmayan ortamlarda, değişik materyal içeren yığınların üzerinde, merdiven üzerinde hareket gibi durumlar için uygundur (Tzafestas, 2011). Uzay çalışmalarında deneysel malzemelerin taşınması, testlerin yapılması gibi durumlarda kullanılan mobil robotlar aynı zamanda restoranlarda servis yapmak, sanayide yük taşıma gibi birçok platformda kullanılmaktadır. Mobil robotlar otomatik hareket edebilme, sensör bilgilerine göre öğrenebilme ve değerlendirebilme özelliklerine sahiptir. Mobil robotların dinamik bir ortamda insan gibi hareket yoluna karar vermesi beklenmektedir. Bütünlük, hızlı cevap verme, daha kısa yol mesafesi, daha az zaman tüketimi gibi yetenekler mobil robotların performans kriterlerini oluşturmaktadır (Yan \& Li, 2016).

Günümüzde geliştirilen teker ve sürüş yapıları ile mobil robotlarda hareket kabiliyeti arttırılmıştır. 1970 lerde Bengt Ilon tarafından Mekanum tekerlek geliştirilmiştir. Mekanum tekerlekler mobil robotların hareket kabiliyetlerini büyük ölçüde arttırmaktadır (Keek, Loh, \& Chong, 2019). Mekanum teker kullanan mobil robotlar ileri, geri, sağ, sol ve çapraz hareketleri açısal dönüş yapmadan yapabilmektedir. Mekanum tekerler mobil robot platformlarında kullanılmaktadır.

Mobil robotların serbest hareketlerinde etraflarını algılamaları gerekmektedir. Çevresini algılanmasında birçok farklı algılayıcı kullanılmaktadır. Kullanılan algılayıcıların başlarında ultrasonik, LIDAR (Laser Imaging Detection and Ranging - Lazer Görüntü Algılama ve Mesafe Ölçümü) ve kamera gelmektedir. LIDAR algılayıcı çeşitli pratik uygulamalarda tercih edilen kullanışlı bir veri toplama aracıdır. LIDAR algılayıcı darbeli lazer 1şı̆̆ı kullanarak değişken mesafe ölçmeyi sağlayan gelişmiş bir uzaktan algılama teknolojisidir (He, Wang, Ghamisi, Li, \& Chen, 2019). Mobil robotların üzerinde sıklıkla kullanılmaktadır. İki boyutlu ve üç boyutlu algılama kapasitelerine sahiptirler. Ayrıca tam tur 360 derece algılama yapabildikleri gibi belirli bir derece aralığında da algılama yapabilmektedirler.

LIDAR algılayıcı, derece bazında nokta bulutu olarak mesafe değerleri vermektedir. Bu değerler ham olarak kontrol birimine gelmektedir ve nokta bulutu anlamlandırılmaktadır. Bunun için mobil robotlarda yüksek işlem gücüne sahip işlemciler kullanılmaktadır.

Mecanum teker yapısının, hareket kabiliyetlerinin, matematiksel denklemlerinin bilinmesi Mecanum tekerli mobil robot platformunun geliştirilmesi için önemlidir (Dickerson \& Lapin, 1991), (Gfrerrer, 2008). Mecanum tekerin kabiliyetlerini bilmek mobil robot platformunun daha verimli geliştirilmesine sebep olmaktadır. Mecanum tekerli mobil robot platformu geliştirilirken tasarımın kinematik ve dinamik tepkilerinin sanal ortamda test edilmesi üretim sonrası oluşacak hataları engellemektedir. Be sebeple Mecanum tekerli mobil robotların matematiksel modellerinin çıkarımı üzerine çalışılmaktadır (Gracia \& Tornero, 2007), (Gfrerrer, 2008), (Tlale \& Villiers, 2008), (Alakshendra \& Chiddarwar, 2017). Mecanum tekerli mobil robot platformlarının hareket ve konum kontrolü önemli bir çalışma alanıdır. Mecanum tekerlerde kayma problemi mobil robot hareket ve konum kontrolünde dikkate alınmaktadır. Kaymanın dikkate alınmaması hareket ve konum kontrollerinde hatalara sebep olmaktadır (Xie, Scheifele, Xu, \& Stol, 2015). Mecanum tekerden oluşan kaymayı önleyebilmek için kaymanın yapısı bilinmelidir (Dickerson \& Lapin, 1991), (Gracia \& Tornero, 2007). Kaymanın yapısı üzerinden kontrol sağlanabildiği gibi hareket esnasında zeminde olan akış görüntüsü kullanılarak da kayma tespit edilmeye çalışılmıştır (Nagatani, Tachibana, Sofue, \& Tanaka, 2000). Çevrenin görüntülerinden yola çıkarak konumlandırma da yapılmaktadır (Vlantis, Bechlioulis, Karras, Fourlas, \& Kyriakopoulos, 2016). Mobil robotun kinematik ve dinamik denklemlerinden yola çıkarak hareketi boyunca alınan örneklemler ile bir sonraki hareketini düzeltme yöntemi ile kayma problemi çözülmeye çalışılmıştır (Viboonchaicheep, Shimada, \& Kosaka, 2003). Kayma faktörünü kaldıracak kinematik modeller sunulmuştur (Gracia \& Tornero, 2007). İvme ölçer, gyro sensörler ve enkoder kullanılarak robotun kayması da engellenebileceği görülmüştür (Kim et al., 2012). Tekerlerlin süspansiyon sistemi ile kullanılmasının hareketlere kararlılık kazandırdığı gözlemlenmiştir (Qian, Zi, Wang, Ma, \& Zhang, 2017). Yapay sinir ağları ile kontrol çalışmaları yapılmıştır (Lu, Zhang, Zhang, Fan, \& Jia, 2018). Robotun önüne ve arkasına iki adet optik fare konularak görsel konum tahmini yapılmaya çalışılmıştır (Cooney, Xu, \& Bright, 2004). Mobil robotun bulunduğu ortam içerisinde engellerden sakınması gerekmektedir. Engellerin mesafe ve açı değerine göre mesafe sensörü kullanılarak, ayrıca lazer mesafe sensörü kullanılarak engelden sakınma üzerine çalışılmıştır (Röhrig, Heß, Kirsch, \& Künemund, 2010), (Zhang \& Li, 2018).

Bir Mekanum tekerin kinematik hesabında kullanılacak parametreler Şekil 1'de verilmektedir. 


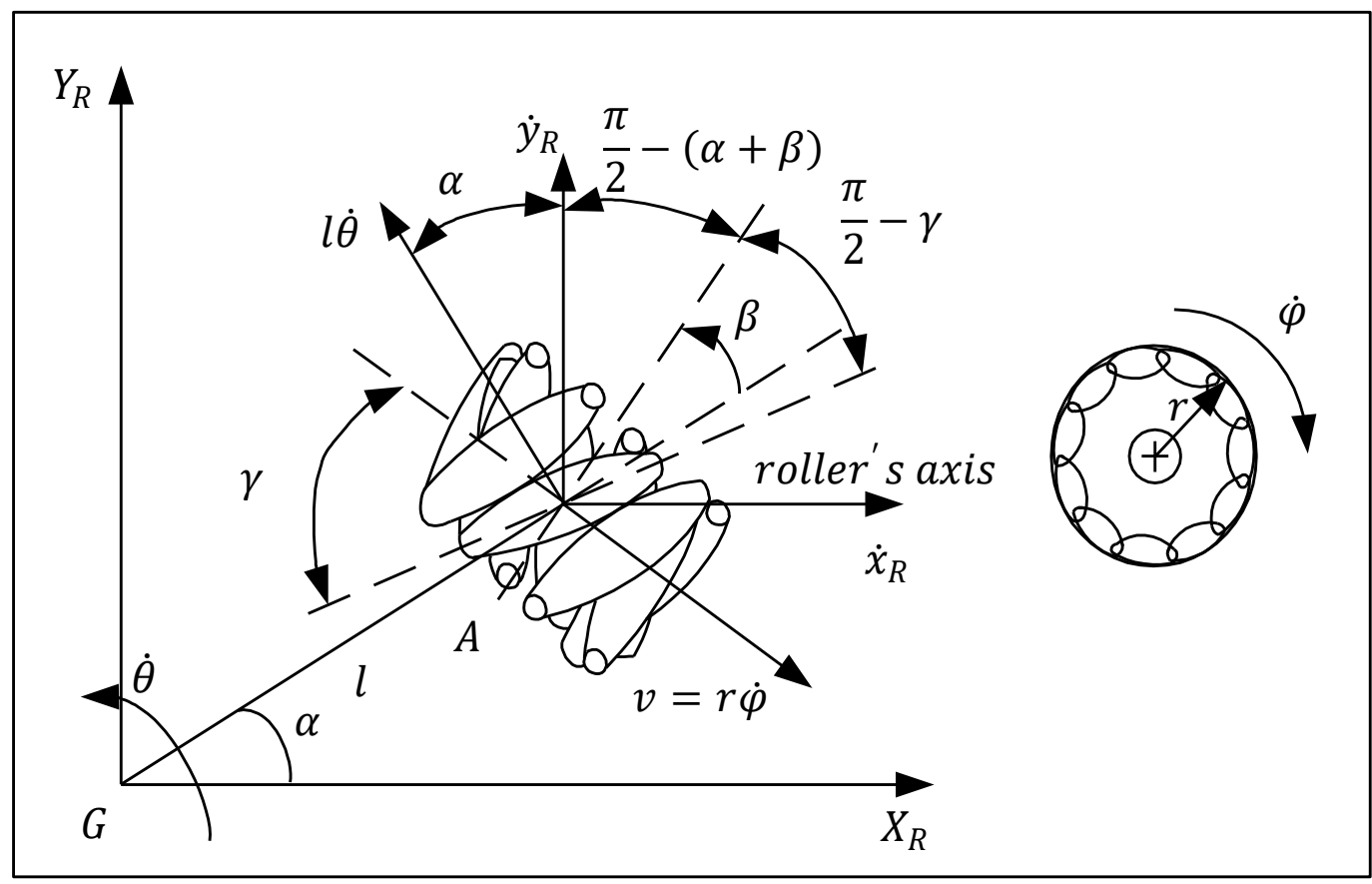

Şekil 1 Mekanum teker parametreleri

Dört Mekanum tekerli mobil robot kinematik denklemleri hesaplanırken Tablo 1'de verilen katsayılar göz önünde bulundurulmaktadır.

Tablo 1 Mekanum teker parametreleri

\begin{tabular}{|l|c|c|c|}
\hline Tekerler & $\alpha_{i}$ & $\beta_{i}$ & $\gamma_{i}$ \\
\hline 1 & $\tan ^{-1}(b / a)$ & $-\tan ^{-1}(b / a)$ & $(\pi / 2+\pi / 4)$ \\
\hline 2 & $\pi-\tan ^{-1}(b / a)$ & $\tan ^{-1}(b / a)$ & $-(\pi / 2+\pi / 4)$ \\
\hline 3 & $\pi+\tan ^{-1}(b / a)$ & $-\tan ^{-1}(b / a)$ & $(\pi / 2+\pi / 4)$ \\
\hline 4 & $2 \pi-\tan ^{-1}(b / a)$ & $\tan ^{-1}(b / a)$ & $-(\pi / 2+\pi / 4)$ \\
\hline
\end{tabular}

Dört Mecanum tekerin eşit mesafelerde montajının yapıldığı varsayımı ile Tablo 1 göz önünde bulundurulup hareket denklemi Eşitlik 1'de ki gibi yazılmaktadır.

$$
\left[\begin{array}{c}
\dot{\varphi}_{1} \\
\dot{\varphi}_{2} \\
\dot{\varphi}_{3} \\
\dot{\varphi}_{4}
\end{array}\right]=-(\sqrt{2} / r)\left[\begin{array}{ccc}
\sqrt{2} / 2 & \sqrt{2} / 2 & l \sin (\pi / 4-\alpha) \\
\sqrt{2} / 2 & -\sqrt{2} / 2 & l \sin (\pi / 4-\alpha) \\
-\sqrt{2} / 2 & -\sqrt{2} / 2 & l \sin (\pi / 4-\alpha) \\
-\sqrt{2} / 2 & \sqrt{2} / 2 & l \sin (\pi / 4-\alpha)
\end{array}\right] \cdot\left[\begin{array}{ccc}
\cos \theta & \sin \theta & 0 \\
-\sin \theta & \cos \theta & 0 \\
0 & 0 & 1
\end{array}\right]\left[\begin{array}{c}
\dot{x}_{I} \\
\dot{y}_{I} \\
\dot{\theta}
\end{array}\right]
$$

Denklemde $\alpha=\tan ^{-1}$ (b/a) olarak alınmaktadır. Jakobiyen matrisi Eşitlik 2'de ki gibi tanımlanmaktadır.

$J=\left[\begin{array}{ccc}\sqrt{2} / 2 & \sqrt{2} / 2 & l \sin (\pi / 4-\alpha) \\ \sqrt{2} / 2 & -\sqrt{2} / 2 & l \sin (\pi / 4-\alpha) \\ -\sqrt{2} / 2 & -\sqrt{2} / 2 & l \sin (\pi / 4-\alpha) \\ -\sqrt{2} / 2 & \sqrt{2} / 2 & l \sin (\pi / 4-\alpha)\end{array}\right] \cdot\left[\begin{array}{ccc}\cos \theta & \sin \theta & 0 \\ -\sin \theta & \cos \theta & 0 \\ 0 & 0 & 1\end{array}\right]$

Verilen denklemler 1şı̆̆ında dört Mekanum tekerli mobil robotun ileri kinematik eşitliği Eşitlik 3 gibi yazılmaktadır.

$\left[\begin{array}{c}\dot{x}_{I} \\ \dot{y}_{I} \\ \dot{\theta}\end{array}\right]=-(\sqrt{2} / 2) r J^{+}\left[\begin{array}{c}\dot{\varphi}_{1} \\ \dot{\varphi}_{2} \\ \dot{\varphi}_{3} \\ \dot{\varphi}_{4}\end{array}\right]$

Burada ki $J^{+}=\left(J^{T} J\right)^{-1} J^{T}$ denklemi J nin tersidir. Şekil 2'de mecanum tekerlekli mobil robotun hareket kabiliyetleri verilmektedir (Lin \& Shih, 2013). 


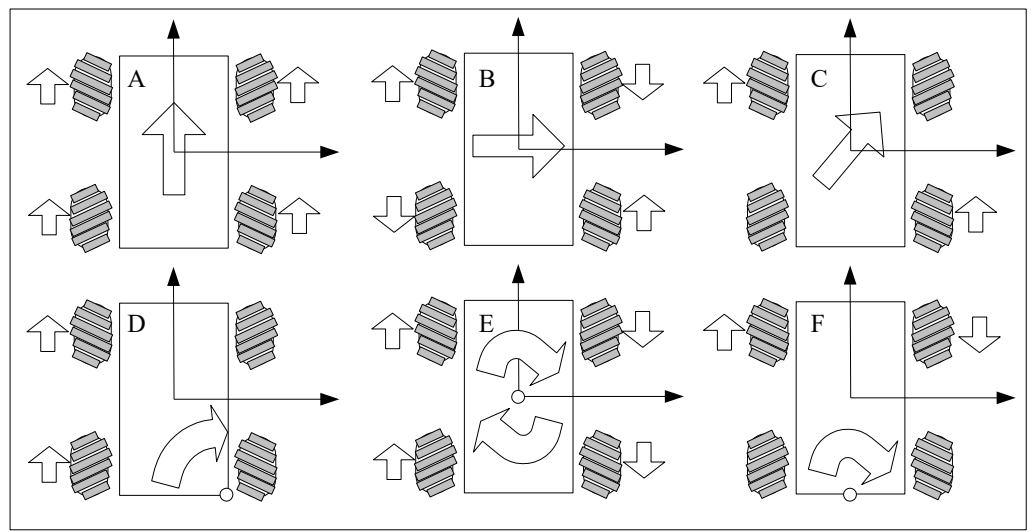

Şekil 2 Mecanum tekerli mobil robot hareket kabiliyetinin görünümü

Mecanum tekerli mobil robotların kinematik ve dinamik özellikleri çok yönlü hareket kabiliyeti olabileceğini göstermektedir. Şekil 2'de Mecanum tekerli mobil robotun bir kısım hareketleri verilmektedir. Bu çalışmada Şekil 2'de görülen A, C ve E hareket tipleri ve bunların tam tersleri kullanılmıştır.

Mekanum tekerli mobil robotların çalışma alanı çok fazladır. Bu çalışmada Mekanum tekerli bir mobil robotun temel hareket kabiliyetleri deneysel olaral araştırılmış ve LIDAR sensörü kullanılarak çevre algısı ile ortam içerisinde çarpışma olmadan dolaşım sağlanması hedeflenmiştir. Çalışmada kullanılan donanımlar, geliştirilen robot ve geliştirilen algoritma materyal ve metot başlığ altında verilmektedir. Deneysel ortam hakkında bilgiler, deneysel çalışmaların nasıl yapıldığı, deneysel çalışmalardan elde edilen çıktılar araştırma sonuçları ve tartışma başlığı altında verilmektedir. Elde edilen sonuçların değerlendirilmesi ve çalışma konusu hakkında genel bir değerlendirme, ileri çalışmalar için öneriler sonuç başlığı altında verilmektedir.

\section{Materyal ve Metot}

Çalışmada kullanılacak dört Mekanum tekerli bir mobil robot platformu geliştirilmiştir. Mobil robot platformu kinematik denklemle uygun bir şekilde geliştirilmiştir (Lin \& Shih, 2013)(Mahmut Çimen, 2018). Tasarımdan son hale kadar olan mobil robot platformu Şekil 3'de verilmektedir.

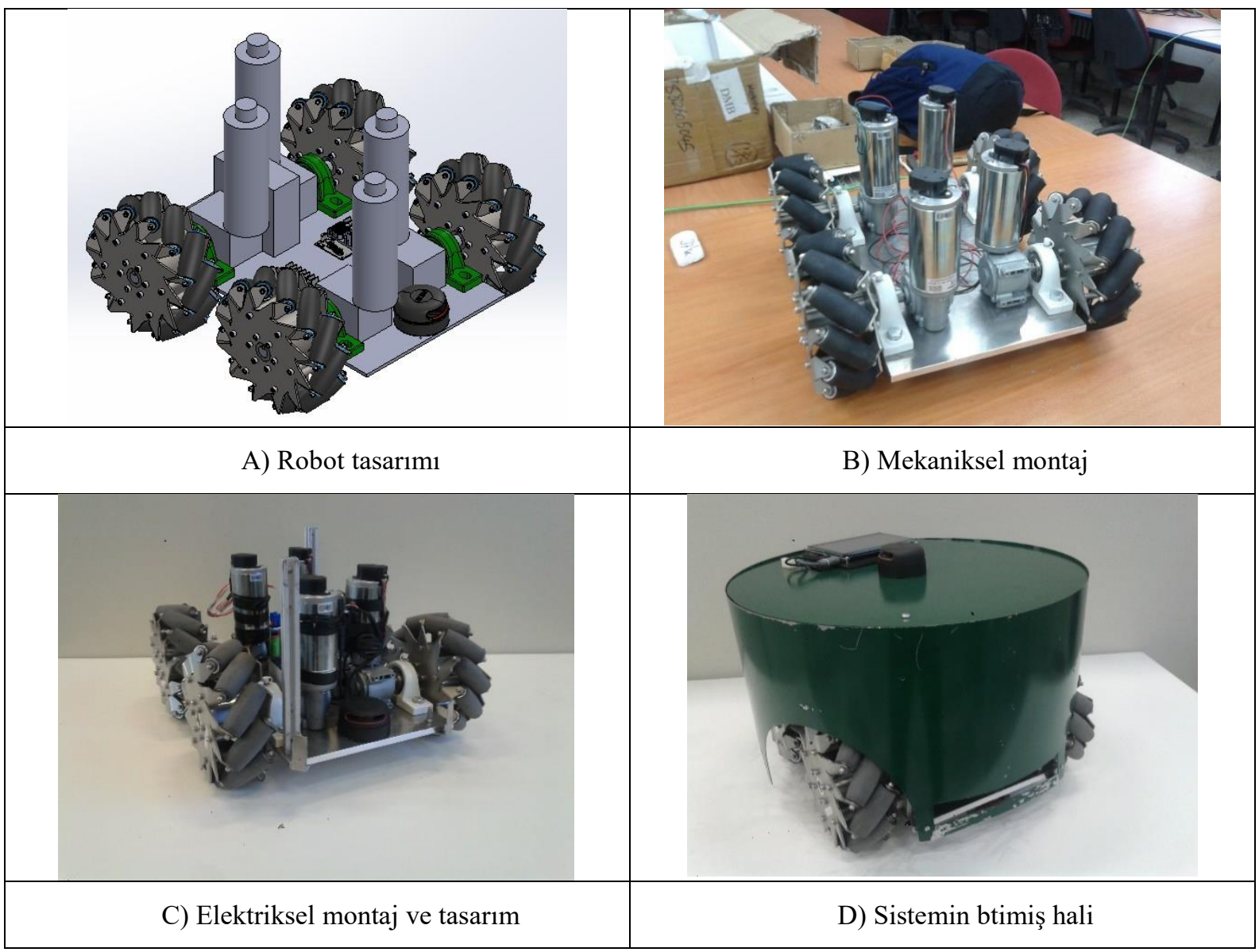

Şekil 3 Geliştirilen robota yapılan işlemlerin aşama aşama görünümleri. 
Sistem Şekil 3'de görüleceği üzere bazı temel birimlerden oluşmaktadır. Bu birimler Şekil 4'te bir blok şema halinde verilmektedir.

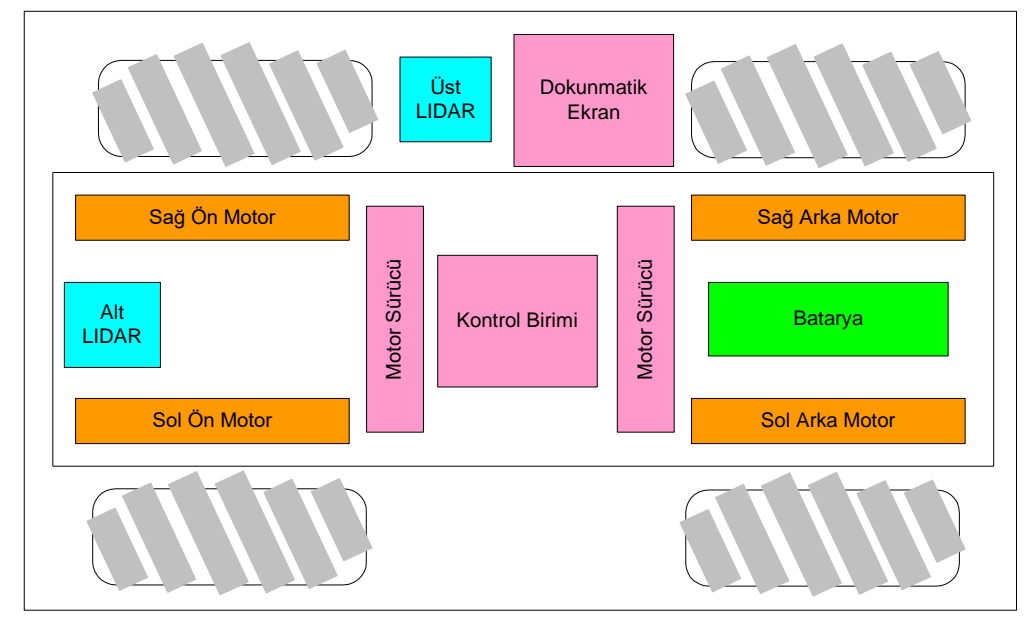

Şekil 4 Sistemin blok şeması.

Şekil 4'te verildiği gibi tüm robotun kontrolünü sağlayan bir temel kontrol birimi vardır. Kontrol birimi LIDAR verilerini anlamlandırmakta ve motor sürücülerine gerekli hareket işaretlerini vermektedir. Kontrol biriminin işlem gücü yüksek olmalıdır. Kontrol birimi olarak INTEL NUC5i7RYB mini bilgisayar kullanılmaktadır. Sayılan birimler bilgisayar ile USB üzerinden haberleşmektedir. Robot hareketi 24V 95W 220r/min DC redüktörlü motor ile sağlanmaktadır. Motor sürücüsü olarak 2x15 A motor sürücü kullanılmıştır. Engellerin ve çevrenin algılanmasında RP A2 LIDAR kullanılmıştır. 360 derece görme kapasitesine sahiptir. Saniyede 8000 nokta uzaklık bilgisi vermektedir. 20m uzaklığı algılamaktadır. Tekerler $203 \mathrm{~mm}$ çapında $78 \mathrm{~cm}$ genişliğinde $150 \mathrm{~kg}$ taşıma kapasitesine sahip Mecanum tekerler kullanılmıştır. Tüm kullanılan donanımlar Şekil 5'de verilmektedir.

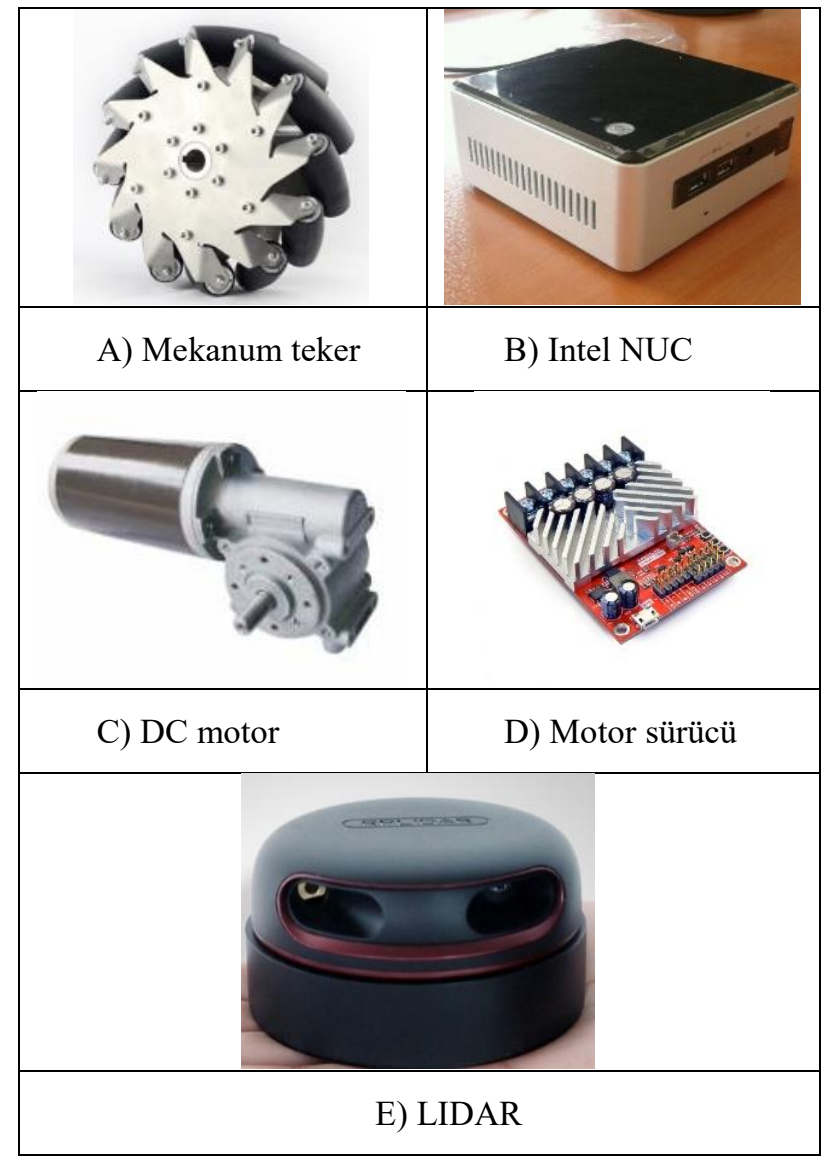

Şekil 5 Kullanılan ekipmanlar.

Çalışmada çevre verileri LIDAR sensör ile ölçülmektedir. Amaç sağ duvar takibi yaparak haritayı tamamlamaktır. Robotun önüne bir engel çıktığı zaman ise robot sola 90 derecelik bir dönüş açısı yapmaktadır. Geliştirilen algoritma Şekil 6'da verilmektedir. 


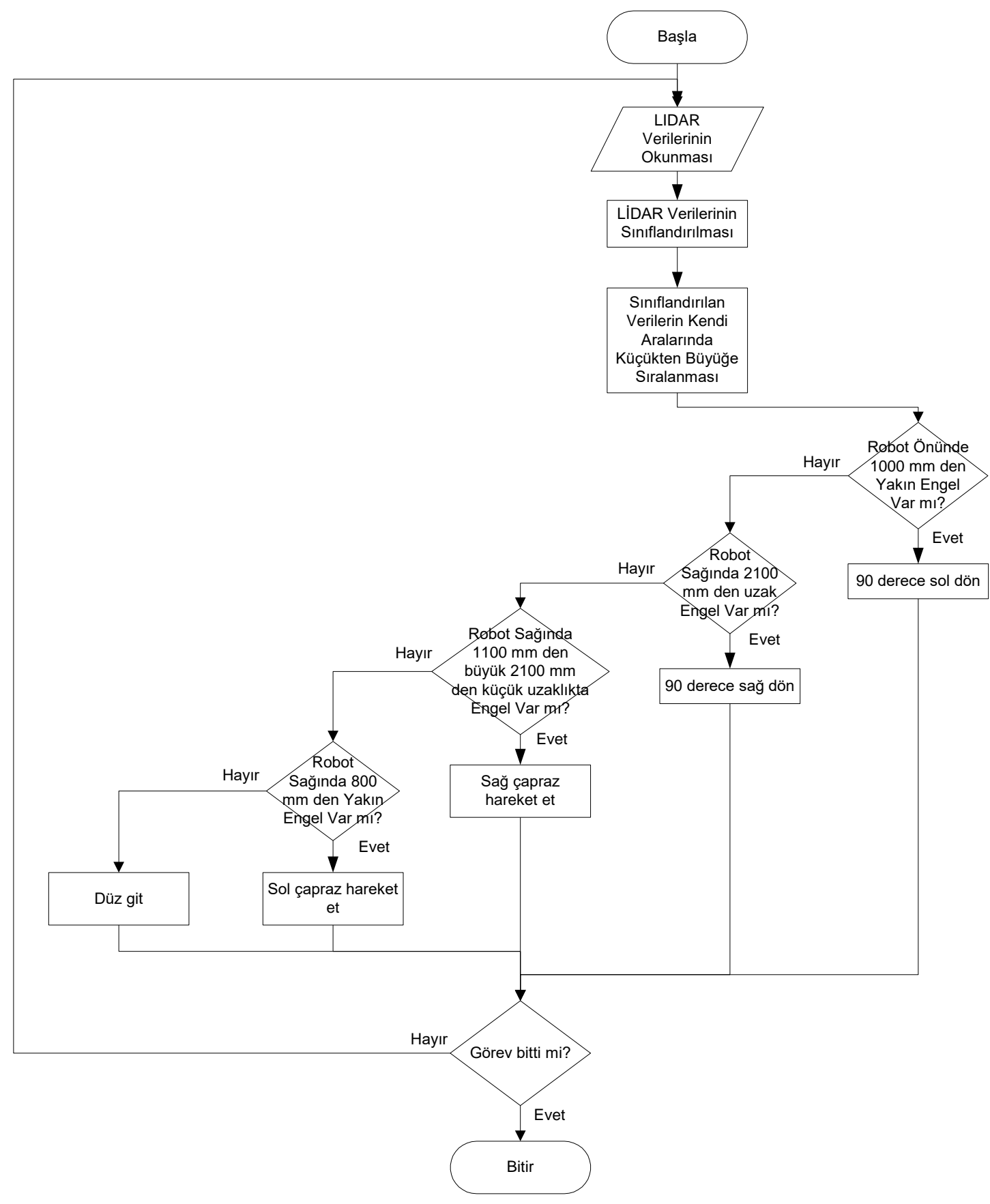

Şekil 6 Programın akış diyagramı

Çalışmada öncelikle LIDAR verileri okunmaktadır. Okunan veriler robotun konumlarında göre sınıflandırılır. Sınıflandırılan veriler kendi aralarında sıralanır. Sıralanan veriler arasında hangi konumda robota ne kadar yakınlıkta engellerin olduğu anlaşılmaktadır. Bu durumda robotun önünde $1000 \mathrm{~mm}$ den yakında bir cisim bulunması halinde robot sola 90 derece dönmektedir. Robotun sağ tarafinda $2100 \mathrm{~mm}$ den büyük bir durum oluşması durumunda robot ara hall lere geldiğini anlamakta ve sağa 90 derece dönmektedir. Robot kendisini sağ duvar ile $800-2100 \mathrm{~mm}$ arasında konumlandırmaktadır. Bu aralıkta düz giderken duvara yaklaşması durumunda sol çapraz ve duvardan uzaklaşması durumda ise sağ çapraz hareketi yapmaktadır.

\section{Araştırma Sonuçları ve Tartışma}

Deneysel çalışma Karabük Üniversitesi Mekatronik Mühendisliği Bölümü Labaratuvarında gerçekleştirilmiştir. Ortam Şekil 7'de verilmektedir. 


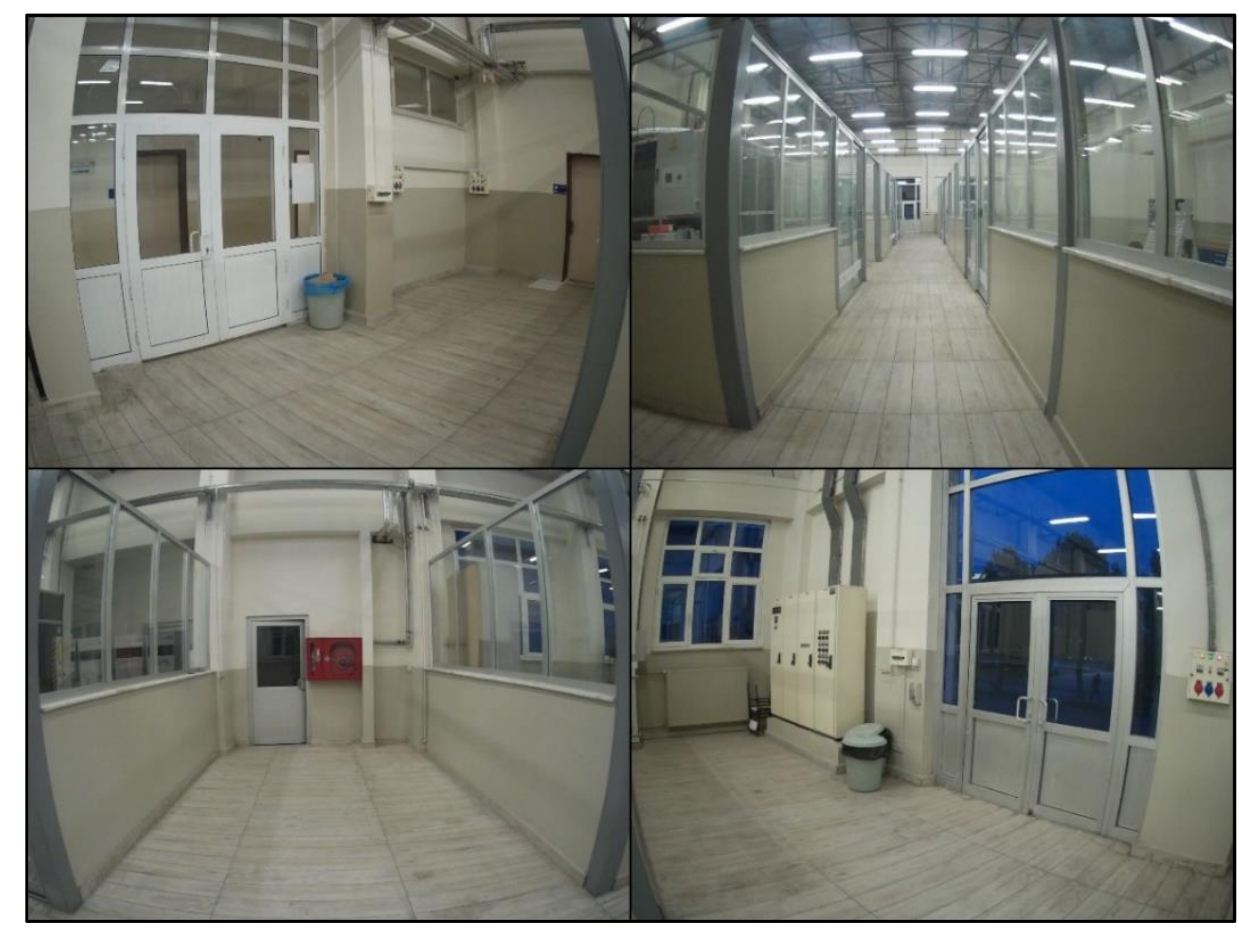

Şekil 7 Deneysel çalışmanın yapıldığı ortam

Deneysel çalışmalar sürekli aynı noktadan başlatılıp yine aynı noktada bitirilmiştir. Arka arkaya deneyler 5 defa tekrar edilmiş̧ir. Her deney robot tam şarj halinde iken yapılmıştır. Robotun çarpışma yaşamadan ortamı taraması beklenmektedir. Deneyler robot üzerine bir kamera yerleştirilerek kayıt altına alınmıştır. Kamera takılmış robot Şekil 8'de verilmektedir.

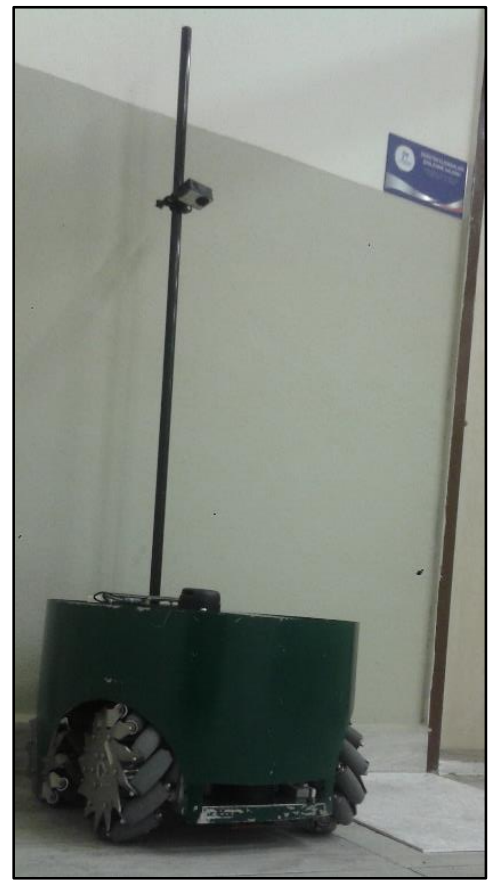

Şekil 8 Robot üzerine konumlandırılmış kamera.

Deney süreci kayıt altına alınmıştır. Kayıt altına alınan görüntüler yüz eşit fotoğraf karesine bölünmüştür. Her kareye ait görüntülerde robotun deney ortamı üzerindeki konumu ortam planı üzerinde yaklaşı olarak işaretlenmiştir. Her deneye ait yaklaşık yüz konum noktası ile deney sonuçları Şekil 9'da ifade edilmektedir. Robot 90 derecelik dönüş esnasında arka arkaya birden fazla bölünmüs anda aynı konumda bulanbilmektedir. Bu sebeple bazı noktalar üst üste konumlandırlmıştır. Robotun 5 deneyde yaptığı hareketler görselleştirilmiştir. İşaretlenen deneysel sonuçlar Şekil 9'da verilmektedir. Şekil 9'da mavi noktalar robotun gidiş yönünde yaptığı hareketleri göstermektedir. Turuncu noktalar ise dönüş yönünde yapmış olduğu hareketleri göstermektedir. Deneylerin başlangıç noktaları kırmızı ok işareti ile gösterilmektedir. Deneyler robot başlangıç noktasına geri geldiğinde son bulmaktadır. Deneyler manuel olarak başlatılıp bitirilmiştir. 


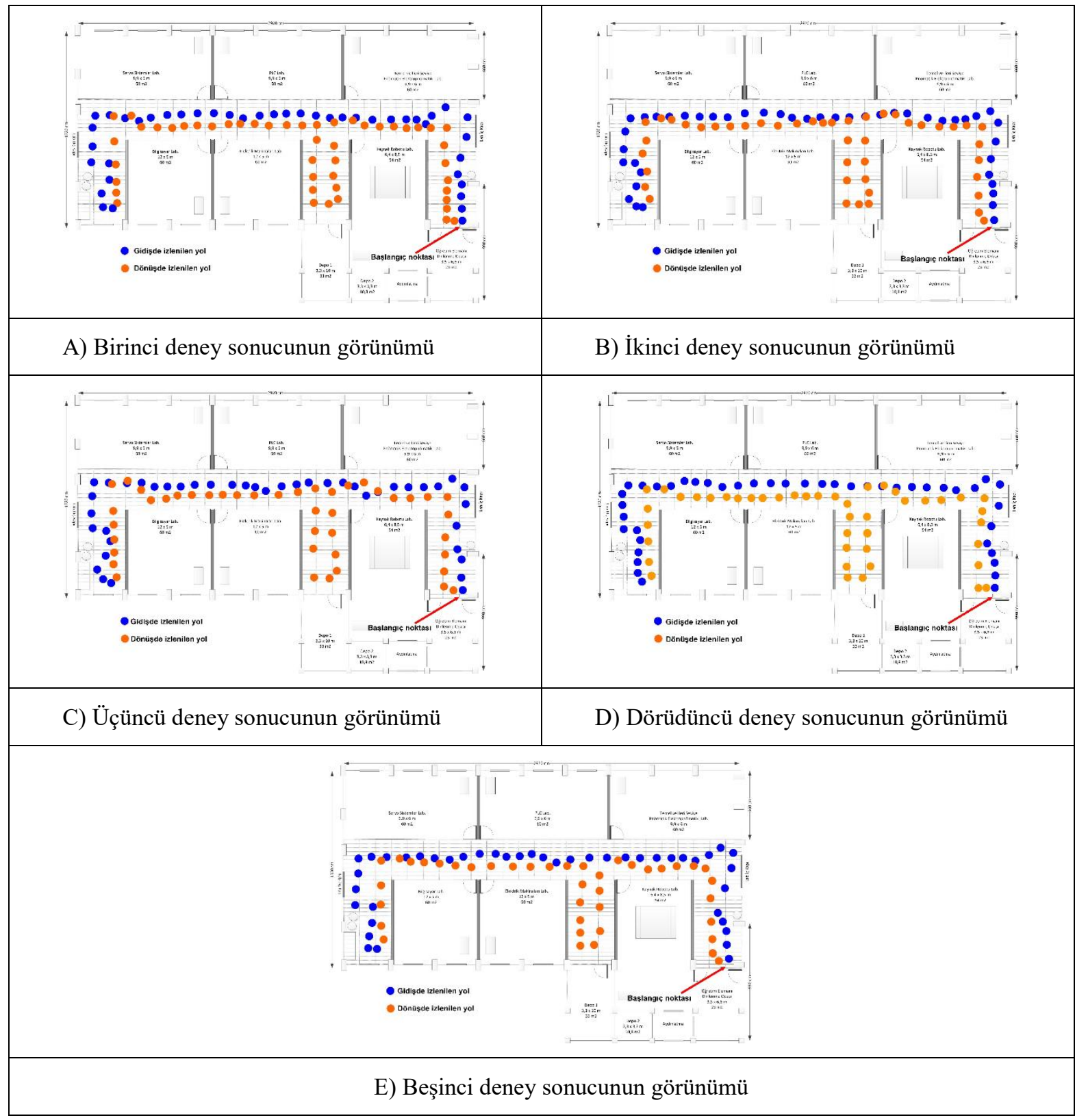

Şekil 10 Deney sonuçları

Robot başlangıç noktasında deneye başlamıştır. Alanı tarayıp geri başlangıç noktasına gelmeyi başarmıştır. Tüm taramayı çevreye çarpmadan yapmayı başardığı görülmektedir. Yalnız ortam zemini parke taşları ile döşeli olduğu için zemin tam pürüzsüz değildir. Bu durumda robot her bir parke taşı üzerinden geçerken Mekanum tekerlerden kaynaklı olarak titreşime maruz kalmaktadır. Bu titreşim robot hareketinde kaymalar meydana getirmektedir. Şekil 10'da görüldüğü üzere robot sürekli doğrusal hareket edememektedir. Robot konumu duvarla olan mesafesine bağlı düzeltilmektedir. Robot önüne bir engel geldiğinde sola dönüs hareketi yapmaktadır. Sağ tarafinda koridorun olduğu anlaşıldığında ise iki saniye ileri hareketi yapmakta ve daha sonra sağa dönüp ileri hareketi yapmaktadır. Bu darvranış ile sağa dönüşlerdeki çarpışma engellenmiştir. Robot sağ duvar ile arasında $80-110 \mathrm{~cm}$ arasında bir mesafe korumaya çalışmaktadır. Hareketindeki dalgalanma bu sebeple olmaktadır. Bazı yerlerde duvara yakın hareket ederken bazı yerlerde de duvardan uzak hareket edebilmektedir. Alan taraması deneylerinin süreleri ve çarpışma durumları Tablo 2'de verilmektedir.

Tablo 2 Deneysel çalışmaya ait veriler

\begin{tabular}{|c|c|c|}
\hline \multicolumn{3}{|c|}{ Alan Taraması Deneyi } \\
\hline Deney Nu. & Deney Süresi & Çarpışma \\
\hline 1. Deney & $00: 04: 45$ & Yok \\
\hline 2. Deney & $00: 04: 42$ & Yok \\
\hline 3. Deney & $00: 04: 49$ & Yok \\
\hline 4. Deney & $00: 04: 45$ & Yok \\
\hline 5. Deney & $00: 04: 42$ & Yok \\
\hline
\end{tabular}


Tablo 2 de verildiği gibi beş deney birbirine yakın sürelerde deneyi bitirmiştir. Ortalama bitirme süresi 4 dakika 45 saniyedir. Üçüncü deney ortalamanın biraz üzerindedir. Şekil 10-C'de robot gidiş yönünde iken ilk koridoru geçmeden hemen önce gidiş yönünde göre çok fazla kaymıştır. Robot yeniden kendini konumlandırana kadar belirli bir süre geçmiştir. Bu sebeple vakit kaybı oluşmuştur.

\section{Sonuç}

$\mathrm{Bu}$ çalışmada dört Mekanum tekerli mobil robot platformu tasarlanmış ve geliştirilmiştir. Mekanum tekerli mobil robotların tasarımında kareselliğe dikkat edilmiştir. Mekanum tekerler robota çok yönlü hareket kabiliyeti sağlar. Bu hareket kabiliyeti robotun engelden sakınırken birden fazla hareket senaryosu kullanabilir hale gelmektedir. Engellerin algılanmasında LIDAR teknolojisinin kolaylıkla başarıyla kullanılabilmektedir. Sabit bir deney ortamında robot performansı test edilmiştir. Her deneyde beş tekrar yapılmıştır. Beş tekrar robot sürekli aynı konumdan başlatılarak yapılmıştır. Bu sayede doğruluk ölçülmeye çalışılmıştır. Birinci deneyde robotun güvenlik amaçlı laboratuvar ortamında alan taraması yapması test edilmiştir. Bu durum için robot sağ tarafındaki duvarı ile belirli bir mesafe de laboratuvar ortamını taramayı başarmıştır. Deney \%100 doğruluk oranı ile başarılı sonuç alınmıştır. Ortalama 4 dakika 45 saniyede alan taraması deneyini bitirmiştir

Mekanum tekerli mobil robotlarda hareket problemi çok fazla olmaktadır. Sadece motor kontrolü ile bu problem çözülememektedir. Çünkü Mekanum tekerlerde yapısı sebebi ile hareket esnasında kaymalar meydana gelmektedir. Bu durum robotun engelden sakınırken izlediği yolun doğrusallığını bozmaktadır. Bu sebeple Mekanum tekerli mobil robot çalışmalarında öncelikle robot pozisyon kontrolünün yapılması hareketi stabilize edecektir. Mekanum tekerin yapısı gereği pürüzsüz zeminlerde fazla titreşim meydana gelmez iken pürüzlü zeminlerde çok fazla titreşim meydana gelmektedir. Titreşimden kaynaklı LIDAR verilerinde bozulmalar ve mekaniksel sistemde yıpranmalar oluşmaktadır. Mekanum tekerlerin bir süspansiyon sistemi ile kullanılması bu sorunu çözebilir.

LIDAR camı görmekte sorun yaşamaktadır. Camları LIDAR cam arasındaki açıya bağlı olarak bazen görebilirken bazende camın arkasındaki nesneleri görebilmektedir. Deneysel çalışmada laboratuvar ortamında camlı bölümler bulunması robotun hareketinde sapmalara neden olmuştur. Sapmaların engellenmesi amacı ile camlı bölgelerde LIDAR mesafesinde camlar kağı̆t ile kapatılmıştır. Bu durum robotdaki sapma problemini çözmüştür.

Mobil robotlarda batarya doluluk durumu çok önemlidir. Çünkü batarya yeterli gücü robota veremediği takdirde LIDAR dan okunan verilerde, robot hızında düşüş gibi problemler yaşanmaktadır. Bunun için batarya doluluk durumunun sürekli kontrol edilmesi gerekmektedir. Batarya doluluk durumunun belirli bir değerin altına düşmesi ile robot çalışmasını ve görev başarısını doğrudan etkilemektedir.

Çalışma sonucunda Mekanum tekerli mobil robotun kapalı alanlarda rahatlıkla çalışabildiği gözlemlenmiştir. Mekanum tekerin hareket kabiliyeti robot hareket esnasında referans açı verildiği taktirde bu açı bozulmadan tüm haritayı o şekilde dolaşabilmesine olanak sağlamaktadır. Bu durumda robot üzerine konumlandırılan kamera yada farklı işlemlerde kullanılacak ve referans yönünün önemli olduğu uygulamalarda kullanılabilirliği görülmüsstür.

İleri çalışmalarda robotun farklı engellerin bulunduğu ortam içerisinde engelden sakınarak ilerlemesi üzerine çalışılacaktır.

\section{Teșekkür}

Bu çalışma KBÜBAP-18-YL-157 kodlu BAP projesi olarak desteklenmiştir.

\section{Kaynakça}

Alakshendra, V., \& Chiddarwar, S. S. (2017). Adaptive robust control of Mecanum-wheeled mobile robot with uncertainties. Nonlinear Dynamics, 87(4), 2147-2169. https://doi.org/10.1007/s11071-016-3179-1

Cooney, J. A., Xu, W. L., \& Bright, G. (2004). Visual dead-reckoning for motion control of a Mecanum-wheeled mobile robot. Mechatronics, 14(6), 623-637. https://doi.org/10.1016/j.mechatronics.2003.09.002

Dickerson, S. L., \& Lapin, B. D. (1991). Control of an omni-directional robotic vehicle with Mecanum wheels. NTC '91 - National Telesystems Conference Proceedings, 323-328. https://doi.org/10.1109/NTC.1991.148039

Gfrerrer, A. (2008). Geometry and kinematics of the Mecanum wheel. Computer Aided Geometric Design, 25(9), 784-791. https://doi.org/10.1016/j.cagd.2008.07.008

Gracia, L., \& Tornero, J. (2007). Kinematic modeling of wheeled mobile robots with slip. Advanced Robotics, 21(11), 1253-1279. https://doi.org/10.1163/156855307781503763

He, X., Wang, A., Ghamisi, P., Li, G., \& Chen, Y. (2019). LiDAR Data Classification Using Spatial Transformation and CNN. IEEE Geoscience and Remote Sensing Letters, 16(1), 125-129. https://doi.org/10.1109/LGRS.2018.2868378

Keek, J. S., Loh, S. L., \& Chong, S. H. (2019). Comprehensive Development and Control of a Path-Trackable Mecanum-Wheeled Robot. IEEE Access, 7, 18368-18381. https://doi.org/10.1109/ACCESS.2019.2897013

Kim, J., Woo, S., Kim, J., Do, J., Kim, S., \& Bae, S. (2012). Inertial navigation system for an automatic guided vehicle with Mecanum wheels. International Journal of Precision Engineering and Manufacturing, 13(3), 379-386. https://doi.org/10.1007/s12541-0120048-9

Lin, L.-C., \& Shih, H.-Y. (2013). Modeling and Adaptive Control of an Omni-Mecanum-Wheeled Robot. Intelligent Control and Automation, 04(02), 166-179. https://doi.org/10.4236/ica.2013.42021

Lu, X., Zhang, X., Zhang, G., Fan, J., \& Jia, S. (2018). Neural network adaptive sliding mode control for omnidirectional vehicle with uncertainties. ISA Transactions, 86, 201-214. https://doi.org/10.1016/j.isatra.2018.10.043 
Mahmut Çimen. (2018). Çok Yönlü Tekerleklere Sahip Bir Çatallı Yükleyicinin Tasarımı ve Kontrolü. Selçuk Üniversitesi.

Nagatani, K., Tachibana, S., Sofue, M., \& Tanaka, Y. (2000). Improvement of odometry for omnidirectional vehicle using optical flow information. IEEE International Conference on Intelligent Robots and Systems, 1, 468-473.

Qian, J., Zi, B., Wang, D., Ma, Y., \& Zhang, D. (2017). The design and development of an Omni-Directional mobile robot oriented to an intelligent manufacturing system. Sensors (Switzerland), 17(9). https://doi.org/10.3390/s17092073

Röhrig, C., Heß, D., Kirsch, C., \& Künemund, F. (2010). Localization of an omnidirectional transport robot using IEEE 802.15.4a ranging and laser range finder. IEEE/RSJ 2010 International Conference on Intelligent Robots and Systems, IROS 2010 - Conference Proceedings, 3798-3803. https://doi.org/10.1109/IROS.2010.5651981

Tlale, N., \& Villiers, M. De. (2008). Kinematics and dynamics modelling of a mecanum wheeled mobile platform. 15th International Conference on Mechatronics and Machine Vision in Practice, M2VIP'08, (3), 657-662. https://doi.org/10.1109/MMVIP.2008.4749608

Tzafestas, S. G. (2011). Introduction to Mobile Robot Control. In Elsevier (1st ed.). Athens, Greece: Elsevier.

Viboonchaicheep, P., Shimada, A., \& Kosaka, Y. (2003). Position Rectification Control for Mecanum Wheeled Omni-directional Vehicles. IECON Proceedings (Industrial Electronics Conference), 1, 854-859. https://doi.org/10.1109/IECON.2003.1280094

Vlantis, P., Bechlioulis, C. P., Karras, G., Fourlas, G., \& Kyriakopoulos, K. J. (2016). Fault tolerant control for omni-directional mobile platforms with 4 mecanum wheels. Proceedings - IEEE International Conference on Robotics and Automation, 2016-June, 23952400. https://doi.org/10.1109/ICRA.2016.7487389

Xie, L., Scheifele, C., Xu, W., \& Stol, K. A. (2015). Heavy-duty omni-directional Mecanum-wheeled robot for autonomous navigation: System development and simulation realization. Proceedings - 2015 IEEE International Conference on Mechatronics, ICM 2015, 256-261. https://doi.org/10.1109/ICMECH.2015.7083984

Yan, Y., \& Li, Y. (2016). Mobile Robot Autonomous Path Planning Based on Fuzzy Logic and Filter Smoothing in Dynamic Environment. 12th World Congress on Intelligent Control and Automation (WCICA), 1479-1484.

Zhang, L., \& Li, D. (2018). Research on mobile robot target recognition and obstacle avoidance based on vision. Journal of Internet Technology, 19, 1879-1892. https://doi.org/10.3966/160792642018111906023 